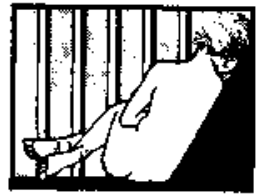

Os técnicos Aidê S. Orsetti, Juarez Alves e Terezinha B. Malta explicam como se iniciou o projeto e quais säo os seus desdobramentos ao ser colocado em prática no período inicial de trabalho:

"O Projeto de Atendimento ao Menino de Rua, desenvolvido na Área Central de Belo Horizonte, teve como ponto de partida o Programa Meninos de Rua, cujo objetivo foi conhecer a vida desses meninos. A partir daí, o trabalho foi planejado em três níveis:

1) na rua - abordagem, apresentação da proposta, manutenção do vínculo estabelecido e triagem para posterior atendimento;

2) na comunidade educativa (a $\mathrm{Ca}$ sa da Rua Ubá) - participaçāo em atividades diversas, visando preparar o menino para se inserir nos serviços prestados pela sociedade e, tendo estas condiçōes, realizar encaminhamentos diversos, dentro do possível: empregos, cursos, família etc.;

3) após encaminhamento - acompanhamento dos meninos, ao se inserirem em novo espaço de vida, através de instituiçōes que prestam serviços junto à comunidade, ou feito diretamente pelos educadores da agência.

\section{O projeto posto em prátlca}

Durante o desenvolvimento do projeto, efetuaram-se modificações nas várias etapas.

A abordagem do menino aconteceu, inicialmente, na rua, durante o primeiro mês. A partir de então, os educadores passaram a atuar apenas na comunidade educativa (a Casa da Rua Ubá). Inovou-se, na prática, a abordagem de novos meninos na $\mathrm{Ca}$ sa, permitindo-se sua presença como visitantes. Assim, um menino desejoso de conhecer a Casa era convidado a visitá-la por um de seus freqüentadores. De acordo com a lei de horário, chegava até às 9 horas, sendo recepcionado e cadastrado por um educador, que the expunha a programação do dia. $O$ menino participava 16 PSICOLOGIA, CIÊNCIA E PROFISSẢO

\title{
Qual é o projeto da Casa?
}

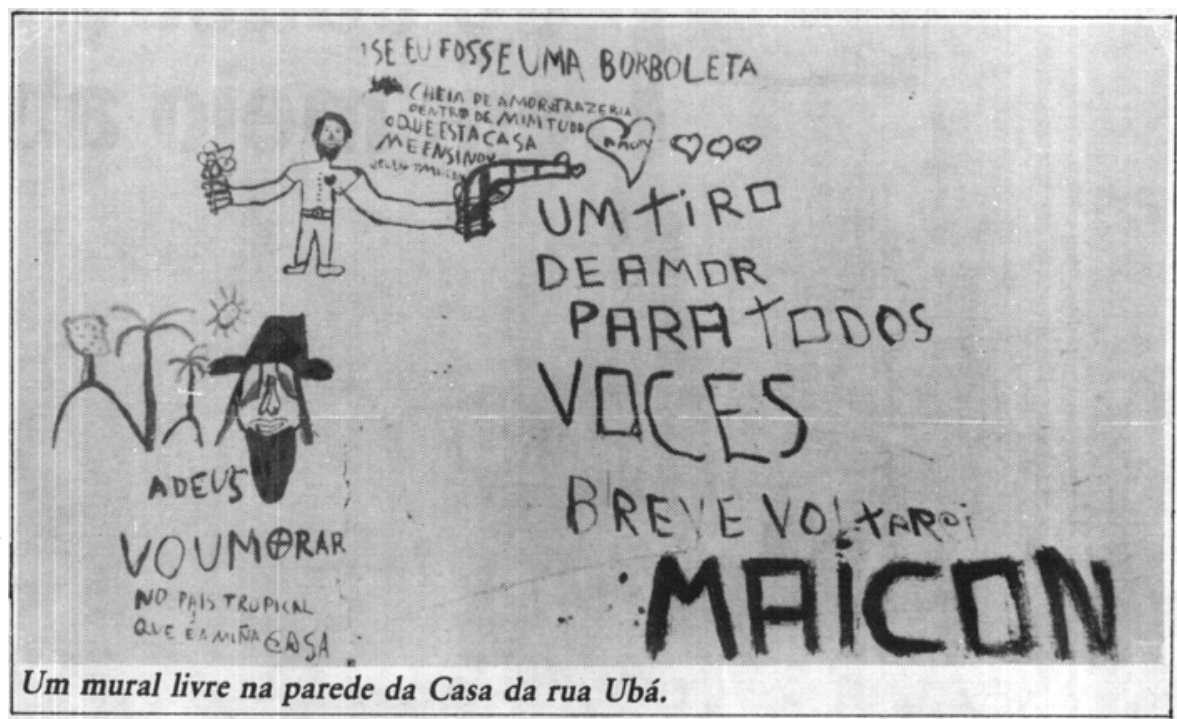

de todas as atividades. Caso gostasse, retornava para a assembléia geral de $2^{2}$ feira, na qual seria decidida sua admissão, em conjunto com os outros meninos.

O retorno dos educadores à rua só acontece quando um menino se ausenta, sem justificativa, durante mais de três dias, ou quando se percebe alguma alteração do trânsito dos meninos da Casa.

Quanto à preparação dos meninos na Comunidade Educativa, inovou-se - planejamento de toda a programação da Casa, através da criação do espaço para as Assembléias (geral, na 2. feira, e extraordinária, quando algum fato a exija).

Para não haver interferência na rotina da Casa, estabeleceu-se a lei para visita de colegas da rua: três tardes por semana.

\section{A geração de rendas e os encaminhamentos}

Atualmente, encontrà-se estruturado um programa de geração de renda. Ele consta de uma pequena oficina de marcenaria, artesanato em couro, fabricação e comercialização de 'chupe-chupe', montagem de uma fábrica de velas e participação em cursos negociados com a UTRAMIG como os de mecânica de autos, eletricista instalador, manicure e pedicure, e salgadeira e doceira. Alguns já se encon- tram em funcionamento: mecânica de autos, manicure e pedicure.

Grande parte do programa ainda não pôde ser colocado em execução por falta de equipamento e verbas para manutenção.

A respeito do programa de lazer da Casa, temos vivenciado um grande espaço para jogos diversos: pinguepongue, peteca etc. Há ainda a opção da TV e a participação em atividades esportivas na comunidade: futebol, natação, corrida e outras.

Quanto a encaminhamentos, muito poucos foram possíveis. Vários meninos manifestaram o desejo de retornar à familia, o que se explica provavelmente pelo fato de haverem encontrado uma relação de afeto com os educadores da Casa. Tentada a experiência, frustraram-se e retornaram ao convivio da Comunidade Educativa. A prática tem revelado a impossibilidade de uma retomada da convivência familiar, talvez em função do rompimento prolongado do elo afetivo e da situação econômico-financeira da familia.

As dificuldades existentes não permitiram ainda o acompanhamento de alguns meninos que se desligaram da Agência. Continua sendo prioridade para a avaliação do trabalho realizado considerar sua validade através dos resultados apresentados pelo egresso da Casa". 


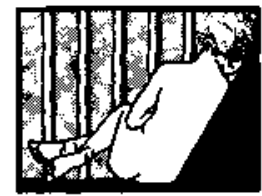

O psicólogo Juarez Alves faz uma descricäo de todas as atividades desenvolvidas na Casa, destacando em particular a importância das Assembléas como uma das formas abertas de organização e de participação de cada um e do conjunto da comunidade:

"O horário para o menino ir à Casa é o da manhã. Se ele não consegue ir pela manhã, perde a chance de estar naCasa naquele dia, já que à tarde ele não é recebido. Ao ser recepcionado, estão à sua disposição um chuveiro com água quente, toalha, bucha, sabonete e roupa para uso interno. $\mathrm{Em}$ seguida, ele toma um lanche, na presença dos educadores. Há, então, uma conversa sobre aquele espaço ou as coisas que aconteceram com ele, recentemente. Inicia-se aí a atividade mais significativa da Casa, no desenvolvimento do Projeto, a Assembléia, que apresentava no início pouca organização. Nesse período ínicial, os meninos se retiravam da Casa no momento em que desejassem.

\section{Os primeiros contatos}

Essas reuniões possibilitaram ao menino revelar, na sua quase totalidade, duas demandas básicas: queriam um lugar para dormir e uma escola para estudar. Isso confirmava dois princípios do projeto: sem albergue e sem alfabetização seria impossível a construção de um projeto de vida junto aos meninos e para eles. Sentimos então que, já passados trinta dias de conhecimento da Casa, era preciso avançar nas etapas do projeto elaborado.

Em primeiro lugar, constatamos a existência de dois grupos na Casa: o dos educadores e o dos meninos que tinham uma presença mais constante e significativa. A interação entre esses dois grupos só foi identificada através da prática, não constando de forma explícita no projeto como ponto fundamental das relaçōes a serem estabelecidas. Se tínhamos o propósito de promover uma nova organização in. terna e externa nas relações com os meninos, era preciso sistematizar ações dentro de uma pedagogia com-

\section{Vivendo um dia inteiro na Casa}

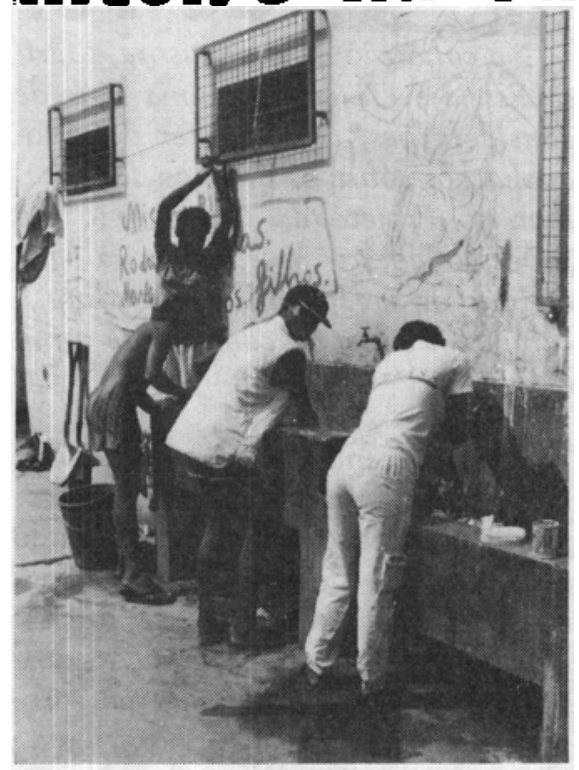

Como atividade de rotina, os meninos cuidam dos objetos pessoais.

promissada e libertadora, em que os espaços da opressão deixassem de existir e o lugar do diálogo fosse construído. É nesse momento que a Assembléia atinge seu caráter sistematizador da socializaçāo buscada a partir da elaboraçāo do projeto. E na Assembléia que fica definido o horário de chegada na Casa - até as nove horas. De oito às nove e trinta, os meninos tomam banho, lavam suas roupas, fazem lanches, enfim, entram em atividades bem pessoais e de forma individual.

\section{Uma rotlna diversificada}

Após as nove e trinta, dois grupos de meninos vão para a alfabetização, um grupo para a musicoterapia, outro grupo para a capoeira e, após uma hora, os grupos se alternam nas atividades desenvolvidas. É bom frisar que o grupo fixo de meninos a serem atendidos diretamente na Casa é de 24, e que seriam distribuídos seis deles para cada atividade. Esse número é apenas referencial, não havendo rigidez na sua composição.

Às onze e trinta, acontece o almoço, ficando livres até às treze e trinta. Nesse momento, todos entram em atividades de caráter formativo, orientadas para o mundo do trabalho, seja atividade de limpeza e de conservaçāo da Casa, seja trabalho em couro ou em madeira. Especificamente, o tra- balho em couro, madeira e chupechupe tem o caráter de geração de renda, estando estas atividades bem aquém do real desejado.

A geração de renda visa a alcançar dois objetivos dos mais significativos: um, o de possibilitar um ganho financeiro para suprir necessidades pessoais, tais como a de ir a um cinema, de poder pagar passagem de ônibus para passeios de fim de semana, tirar documentos, e outros, mas jamais pretende a obtenção de uma renda que venha a suprir todas as necessidades do menino. $O$ segundo objetivo é o de facilitar a elaboração de novas formas de ganhar dinheiro, (além do roubo, tão comum no cotidiano dos bandos). Ageração de renda tem sido um desafio no sentido de encontrar atividades que garantam rentabilidade com custos baixos e que permitam o desenvolvimento e o conhecimento emocional do menino.

As dezesseis horas, fazem um lanche e às dezesseis e trinta são liberados para o pernoite (albergue).

Nessas atividades diárias, temos na sexta-feira às onze horas o horário de lavar roupa da Casa. Os meninos receberam roupas para uso durante as atividades, tendo o compromisso de conservá-las, já que elas têm um período de duração e somente após esse tempo é que recebem novas peças.

Por que fazer Assembléla?

Temos, também, reconhecida como a linha mestra das relações na Casa uma Assembléia na segundafeira às nove e trinta, quando as leis da Casa são formuladas, todas as propostas são discutidas, inclusive a admissão de novos elementos e os compromissos de cada um acertados.

A Assembléia é o momento em que todos - o grupo de meninos e o de educadores - se agrupam para uma discussāo em comum. Aparecem, então, as dificuldades afetivas, a negação aos compromissos duradouros, 0 desejo de estar na Casa e o não saber como preservá-la etc. E nesse estar junto especial que surgem os temas que orientam os conteúdos a serem trabalhados. E aí que o menino reflete e descobre que ele não tem uma consPSICOLOGIA, CIÉNCIA E PROFISSĀO 17 